\title{
Judaïsme et Sexualité
}

\author{
Grand Rabbin G.HAIK \\ 17, rue Alsace Lorraine - 31000 Toulouse
}

\section{Le Judaïsme confère à la sexualité une importance exceptionnelle.}

Le fait que dans les textes, l'on s'étende sur la sexualité illégale avec de nombreux interdits (inceste, adultère, relations en période de règles ne doit pas faire oublier que s'attache aussi à la sexualité une valeur positive.

Ce n'est pas pour rien que ce soit la zone génitale masculine qui porte le sceau de l'Alliance.

Mais, d'une manière encore plus probante, l'acte sexuel fait l'objet de deux Mitsvat, c'est-à-dire de deux commandements religieux positifs à appliquer dans le cadre du mariage, ce qui exclut pour le moins une conception où le mariage ne serait qu'une concession aux faiblesses de l'homme et où la chasteté serait l'idéal.

Le premier de ces deux commandements est celui de la procréation grâce à laquelle l'homme se trouve l'associé de D... dans l'oeuvre de la Création.

Cependant, même lorsque les relations sexuelles sont dépourvues de toute finalité reproductrice (femme stérile, enceinte ou ménopausée), elles font l'objet d'une deuxième Mitsvat appelée Mitsvat Ona. Le mot Ona peut se traduire par " période de retrouvailles ", ce qui laisse entendre qu'à l'intérieur du couple, il y a lieu de prévoir ces temps qui permettent de réaliser l'harmonie sur le plan sexuel.

L'amour, dès lors, constitue un impératif religieux, ce que suggère déjà le texte bien connu de la Genèse : "C'est pourquoi, l'homme lais- sera son père et sa mère ; Il s'attachera à sa femme et ils deviendront une seule chair."

Le Talmud va encore plus loin avec Rabbi Ellezer qui affirme : " Tout homme qui n'a pas de femme, n'est pas un homme (nous ajouterons à titre de commentaire plausible : N'est pas un homme accompli)".

Dans cette Mitsvat Ona, on fait devoir au mari de ne pas oublier le désir de son épouse et de satisfaire son attente considérée comme bien légitime.

Mais il faut savoir qu'au delà de l'idée du plaisir, le Judaïsme inscrit cette harmonie sexuelle dans une entreprise infiniment plus vaste, plus ambitieuse : la réalisation de l'union authentique et profonde entre l'homme et la femme, que constitue l'un des secrets de l'épanouissement et de l'équilibre.

Dès lors, qu'est-ce-que le Judaïsme peut proposer d'autre qu'une forte opposition à une exploitation de progrès scientifiques appliqués au sexe masculin, qui dans ses objectifs irait à l'encontre de ses positions fondamentales?

Toutefois, ce que l'on doit dire, c'est que les autorités religieuses sont en mesure de nuancer leurs décisions sur la base d'un savoir médical ou psychologique qu'ils découvrent et dont ils tiennent compte.

Ainsi, à l'intérieur du couple, si l'on est déjà habitué à l'examen des procédés qui rendront possible la procréation, l'on montrera le même intérêt pour les possibilités, sur le plan sexuel, de renforcer le couple et plus encore, d'éviter sa dislocation. 
On ne peut pas ignorer la souffrance qu'engendrent l'impuissance ou la mauvaise qualité de la relation sexuelle. L'on peut dès lors, considérer qu'il s'agit d'une affection qu'il faut soigner et pour laquelle de nouveaux moyens feront l'objet d'un examen intéressé et non d'un refus global.

En ce qui concerne la sexualité extra-conjugale, les rabbins savent qu'elle s'est largement répandue, mais comment voulez-vous qu'ils examinent les modalités de son exercice, lorsqu'ils la contestent dans son principe, alors que la domination des sens et le mariage consacré sont des constantes de l'exigence juive.

$\mathrm{Si}$, à propos du Sida, face à une permissivité sexuelle qu'ils constatent avec regret, ils ont été amenés à rappeler le principe sacro-saint de la préservation de la vie, quelle ouverture peut-on attendre par rapport au sujet d'aujourd'hui s'il devait se confiner aux moyens médicaux d'obtenir le plaisir tous azimuts.

Nous constatons, avec satisfaction, que les médecins plus directement concernés par les nouvelles avancées dans le domaine de l'andrologie, sont animés par le souci de l'éthique et qu'ils font preuve de prudence face à une éventuelle explosion qui pourrait s'avérer très préjudiciable.

Nous ne préjugeons pas de l'aboutissement de leur louable réflexion.

Mais, il me paraît certain que les représentants du Judaïsme, en continuant de délivrer leur message spécifique, diront encore à ceux qui les consultent que tout ce dont l'homme peut disposer - et là, les choses deviennent énormes au point de donner le tournis- ne devient pas pour autant permis.

Toutefois, le moins que l'on puisse demander c'est que comme dans d'autres domaines, et ceci par souci de salubrité publique, des garde-fous soient mis en place et que par exemple, les médecins restent ceux qui prescrivent.

Leur rôle risque de n'être pas facile car comment pourront-ils être sûrs que les utilisateurs n'iront pas bien au-delà de ce qu'eux mêmes pourront prescrire en toute conscience? 